\title{
111 HOW GENDER AND AGE AFFECT TOLERANCE OF COLONOSCOPY
}

W Lai, M Fung, J Vatish, R Pullan, M Feeney Torbay Endoscopy Unit, Torbay Hospital, Torquay, UK

\subsection{6/gutjnl-2013-305143.111}

Introduction The aim of a colonoscopist is to perform the procedure safely within a reasonable time limit, and minimise any discomfort/pain caused to their patients. It is therefore useful to recognise factors that can influence patients' tolerance of colonoscopy as part of pre-procedure planning.

Aims/Background We collected data from a local endoscopy unit to evaluate the effect of gender and age on patients' experience of the procedure.

Method 354 patients who had bowel cancer screening colonoscopy (and found to have polyps) between January 2010 and December 2011 were identified from the BCSP database (Oracle BI Interactive Dashboards). Endoscopy reports were drawn from Scorpio $\odot$ reporting system, with the patients' comfort level recorded using the Modified Gloucester Discomfort Score (Figure 1).

Results Male patients had a lower mean comfort score (i.e. better tolerated) than female patients $(-0.5,95 \%$ CI -0.47 , -0.53 ) (Table 2). This is consistent with the lower mean fentanyl requirement in men compare to women $(-6 \mathrm{mcg}$

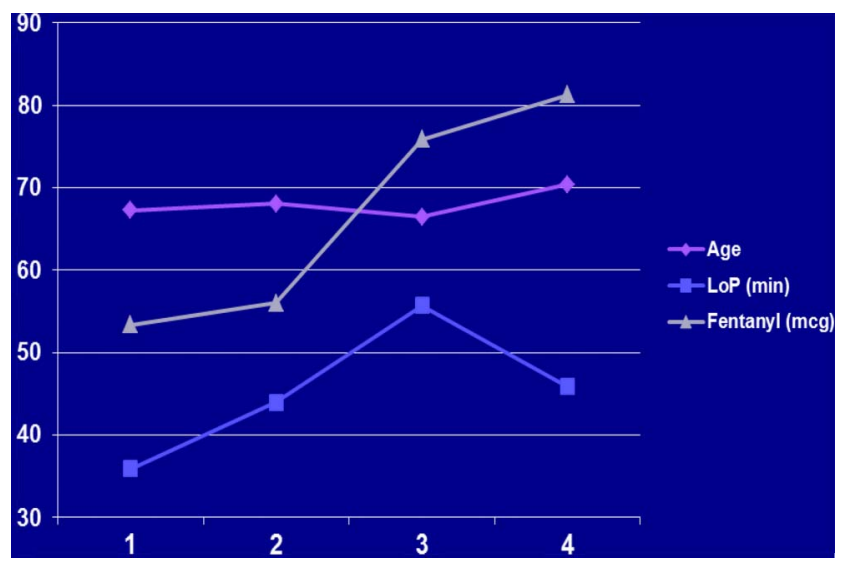

Figure 1

\begin{tabular}{ll}
\hline \multicolumn{2}{l}{ Table 1} \\
\hline Comfort Level (Modified Gloucester Discomfort Score) \\
\hline 0 & Not specified/entered (legacy record) \\
1 & None-resting comfortable throughout \\
2 & One or two episodes of mild discomfort, well tolerated \\
3 & More than two episodes of discomfort, adequately tolerated \\
4 & Significant discomfort, experienced several times during procedure \\
5 & Exterme discomfort frequently during procedure \\
\hline
\end{tabular}




\section{Abstracts}

\section{Table 2}

\begin{tabular}{lllll}
\hline Gender & Number & $\begin{array}{c}\text { Mean } \\
\text { Comfort } \\
\text { Score }\end{array}$ & $\begin{array}{c}\text { Mean Fentanyl } \\
\text { Requirement } \\
\text { (mcg) }\end{array}$ & $\begin{array}{c}\text { Mean Midazolam } \\
\text { Requirement (mg) }\end{array}$ \\
\hline Male & 247 & 1.40 & 53.4 & 1.82 \\
Female & 107 & 1.90 & 59.4 & 1.86 \\
\hline
\end{tabular}

\section{Table 3}

\begin{tabular}{llll}
\hline $\begin{array}{l}\text { Comfort } \\
\text { Score }\end{array}$ & $\begin{array}{l}\text { Mean } \\
\text { Age }\end{array}$ & $\begin{array}{l}\text { Mean } \\
\text { LoP }(\min )\end{array}$ & $\begin{array}{l}\text { Mean Fentanyl } \\
\text { Requirement }(\mathbf{m c g})\end{array}$ \\
\hline $\mathbf{1}$ & 67.3 & 35.9 & 53.4 \\
$\mathbf{2}$ & 68.1 & 44.0 & 56.0 \\
$\mathbf{3}$ & 66.5 & 55.7 & 75.9 \\
$\mathbf{4}$ & 70.4 & 45.9 & 81.3 \\
\hline
\end{tabular}

$+/-0.1072)$. The comfort score also showed a positive correlation when plotted against age, length of procedure and fentanyl requirement (Tables 3 and Figure 1).

Conclusion The reason for the less-tolerated colonoscopies for women might be due to previous gynaecological operations and possible longer colon 1 (which predispose to looping). Elderly patients may tolerate the procedure less due to previous abdominal surgery and looping of laxer and longer colons 1. The longer length of procedure suggests a more difficult examination which could contribute to patient discomfort. The amount of Fentanyl used was directly proportional to the comfort score as the endoscopists responded to the patients' discomfort. 